\title{
Medical perspective in testicular ischemia-reperfusion injury (Review)
}

\author{
SALVATORE ARENA $^{1}$, ROBERTA IACONA ${ }^{2}$, PIETRO ANTONUCCIO $^{1}$, TIZIANA RUSSO ${ }^{1}$, \\ VINCENZO SALVO $^{3}$, ELOISA GITTO $^{3}$, PIETRO IMPELLIZZERI ${ }^{1}$ and CARMELO ROMEO ${ }^{1}$ \\ ${ }^{1}$ Department of Human Pathology in Adult and Developmental Age 'Gaetano Barresi', \\ Unit of Paediatric Surgery, University of Messina, I-98125 Messina, Italy; ${ }^{2}$ Department of Paediatric Surgery, \\ John Radcliffe Hospital, Oxford University Hospital, Oxford OX3 9DU, UK; ${ }^{3}$ Department of Human Pathology in Adult and \\ Developmental Age 'Gaetano Barresi', Neonatal and Intensive Care Unit, University of Messina, I-98125 Messina, Italy
}

Received July 20, 2016; Accepted January 6, 2017

DOI: $10.3892 /$ etm.2017.4289

\begin{abstract}
Testicular torsion or torsion of the spermatic cord is one of the most serious urological conditions. It causes testicular injury, which potentially leads to male subfertility. The turning of the spermatic cord and spermatic structures around themselves results in biochemical and histological changes; however, following testicular detorsion, tissues undergo reperfusion that causes more severe damage than that induced by ischemia. Since the primary causes of testicular damage are reactive oxygen species production, an increase in intra-mitochondrial calcium concentration and an increased rate of cellular apoptosis, different medications may potentially be effective. It seems that several medications, experimentally and sometimes clinically, serve an adjuvant role in the cellular damage that occurs following ischemia-reperfusion. Antioxidants, calcium channel blockers, phytotherapeutical medicinals, anaesthetics, hormones and platelet inhibitors may potentially create a solid basis for an adjuvant restoring therapy and ameliorate testicular function following torsion. The current study aimed to review the relevant literature and discuss the actions of a number of molecules that may protect the testes during ischemia/reperfusion injury.
\end{abstract}

\section{Contents}

1. Introduction

2. Agonists of erythropoietin receptors (EPO-R)

Correspondence to: Professor Salvatore Arena, Department of Human Pathology in Adult and Developmental Age 'Gaetano Barresi', Unit of Paediatric Surgery, University of Messina, Viale Gazzi - Policlinico, Block NI, I-98125 Messina, Italy

E-mail: salarena@unime.it

Key words: testicular torsion, ischemia/reperfusion injury, antioxidants, phytotherapy, calcium channel blocker, modulators of inflammation, interaction with neutrophils

\author{
3. Anaesthetics \\ 4. Antioxidants \\ 5. Calcium channel blockers \\ 6. Interaction with neutrophils \\ 7. Interaction with renin-angiotensin system (RAS) \\ 8. Modulators of inflammation \\ 9. Physical therapies \\ 10. Phytotherapeutics \\ 11. Platelet inhibitors \\ 12. Sex steroid precursors \\ 13. Vasodilator agents \\ 14. Other mechanisms \\ 15. Conclusions
}

\section{Introduction}

Testicular torsion or torsion of the spermatic cord is one of the most serious urological emergencies encountered and is generally identified in newborn and adolescent males (1). It causes testicular injury, which potentially leads to the development of male subfertility when misdiagnosed and inappropriately treated (2). The turning of the spermatic cord and spermatic structures around themselves results in biochemical and histological changes and ultimately, the development of testicular dysfunction (3). Due to testicular torsion, blood flow to the testicular tissues is interrupted and this interruption leads to ischemia during which energy rich phosphates (ATP) are depleted and levels of their degradation products, such as hypoxanthine, rise $(4,5)$.

Following testicular detorsion, tissues undergo reperfusion, causing more severe damage than that induced by ischemia (6). Ischemia-reperfusion (I/R) injury occurs when blood circulation is restored following an episode of acute ischemia $(7,8)$. In this type of injury, the blood supply to the tissue is initially interrupted, damaging metabolically active tissues. However, the restoration of blood flow to the tissues initiates a paradoxic cascade of events, including free oxygen radical production, intracellular calcium overload and lipid peroxidation, leading to further cellular and tissue damage (8). Following the onset of ischemia, adenosine triphosphate is degraded to hypoxanthine 
and xanthine dehydrogenase is converted to xanthine oxidase (9). Testicular ischemia/reperfusion (tIR) activates a complex cascade of cellular and molecular reactions that are not yet fully understood. However, a number of studies suggest that restoration of blood supply to ischemic testes is associated with the excessive production of reactive oxygen species (ROS) and the generation of testicular oxidative stress (10) that activates mitogen activated protein kinases (11-13). tIR leads to lipid peroxidation, protein denaturation, DNA damage and activation of the apoptotic machinery (11). Furthermore, it has been determined that in tIR, activated neutrophils adhere to microvascular endothelium and subsequently emigrate and secrete the enzyme myeloperoxidase, which catalyses the formation of ROS. Testes are sensitive to free radical damage. Under normal conditions, enzymatic antioxidant defence systems, including glutathione peroxidase (GPx), superoxide dismutase (SOD) and catalase (CAT), protect those cells from free radical damage (14). During tIR, alterations in cellular and mitochondrial $\mathrm{Ca}^{2+}\left(\mathrm{mCa}^{2+}\right)$ depositions are critically important $(15,16)$. Levels of $\mathrm{mCa}^{2+}$ increase via $\mathrm{mCa}^{2+}$ uniporter channels that increase intracellular $\mathrm{Ca}^{2+}$. Excessive $\mathrm{mCa}^{2+}$ loads initiate irreversible events that result in cell apoptosis through permeability transitions and pore formation (17).

It has been demonstrated in animal models that a number of substances have some benefit at reducing testicular reperfusion injury (18). The current study used papers from the National Center For Biotechnology Information database (https://www. ncbi.nlm.nih.gov/pubmed/) from 2005, using the search terms 'testicular ischemia reperfusion injury' and 'ischemia reperfusion injury testis'. Papers that did not focus on the medical treatment of tIR were excluded.

\section{Agonists of erythropoietin receptors (EPO-R)}

EPO-R and darbepoetin alfa. EPO-R have been detected in different types of tissue including brain, spinal cord, heart and testes, and exhibit neuroprotective, anti-apoptotic, antioxidant, anti-inflammatory and angiogenic activity (19). EPO and the long acting EPO analogue darbepoetin alfa may have a protective effect on testicular I/R injury $(20,21)$.

\section{Anaesthetics}

Dexmedetomidine (Dex). Dex is a selective and potent $\alpha 2$-adrenoceptor agonist, approved for use by the US Food and Drug Administration in 1999 to sedate patients hospitalized in intensive care settings. In addition to sedative and analgesic effects, it has been demonstrated that Dex has organ-protective effects in a number of inflammatory models, including tIR injury (22). It has been suggested that sympatholysis may be a property of Dex, due to its mechanism of action via presynaptic $\alpha$-adrenoceptors. Through this mechanism, Dex may reduce the noradrenaline release induced by ischemia, thus reducing overall oxidant status (23).

Morphine. Morphine administration decreases I/R injury in the rat heart and protects the rabbit kidney against oxidative stresses resulting from I/R $(24,25)$. It has been determined that morphine increases levels of ipsilateral intratesticular antioxidant markers during the reperfusion phase that follows unilateral testicular torsion, and this is reflected in lower testicular malondialdehyde (MDA) levels (26). This effect seems to be mediated through opioid receptors. The observed effect of morphine may be due to its impact on neutrophils and its direct scavenging action against peroxynitrite (26).

Propofol. Propofol seems to have antioxidant effects that inhibit lipid peroxidation by forming relatively unreactive free radicals capable of breaking the production chain of radicals that are potentially damaging to cell membranes in tIR injury (27).

\section{Antioxidants}

$\alpha$-Lipoic Acid. $\alpha$-Lipoic Acid decreases the cellular damage and apoptosis occurring during testicular I/R injury in rats (28). Additionally, it has been reported that $\alpha$-lipoic acid administration has significant protective effects against oxidative stress by decreasing GPx and SOD activity. Furthermore, $\alpha$-lipoic acid reduces MDA levels, which is considered to be an important indicator of lipid peroxidation (28).

Dimethylsulfoxide (DMSO). DMSO exerts a protective effect against testes lipid peroxidation injury caused by I/R in rats. The increase in GSH levels during reperfusion in DMSO-treated rats favours the hypothesis that the use of this substance in the pretorsion period may attenuate the damaging effects of tIR injury (29).

Ebselen. Ebselen is a type of synthetic antioxidant that has a wide spectrum of therapeutic actions. It exhibits anti-atherosclerotic and renoprotective effects; therefore, clinical trials are currently investigating its efficacy against stroke and reperfusion injury (30). It is considered an antioxidant and ROS scavenger and reduces the oxidative biochemical and histopathological damage that occur following tIR (31).

Edaravone. Edaravone, a free-radical scavenger, is used for the clinical treatment of cerebral ischemia in Japan. It has been reported that edaravone reduces levels of 8-hydroxydeoxyguanosine, a marker of oxidative DNA damage (3). Moreover, edaravone seems to protect germ cells (3).

Mannitol. Mannitol is an intravascular volume expander with free radical scavenging properties, as well as being an osmotic diuretic and it is has been reported that it reduces ischemic renal damage (32). Mannitol infusion also has a protective effect against experimental tIR injury (33).

Melatonin. Melatonin is a potent antioxidant and a free radical scavenger that promotes the formation of antioxidant enzymes and inhibits lipid membrane peroxidation (34-37). It has been demonstrated that melatonin, with or without ozone, decreases levels of MDA, thus limiting the tissue injury that occurs following tIR $(36,37)$.

Selenium. Selenium is a well-known antioxidant that increases glutathione peroxidase activity $(38,39)$. It acts by 
reducing the oxidative stress and apoptosis that result from testicular tIR injury and therefore protects against testicular damage (40).

Statins. Statins are recognized as atypical anti-inflammatory agents that possess various immunomodulatory effects in addition to their conventional lipid-lowering properties (41). The precise mechanism by which statins exert this anti-inflammatory effect is currently unclear. Some studies have demonstrated that statins serve a protective role in tIR injury by inducing heme-oxygen-1 in endothelial and macrophage cells, leading to a reduction in caspase-3 activity and germ cell apoptosis $(41,42)$.

Polydeoxyribonucleotide (PDRN). Administration of PDRN, an active fraction of a preparation extracted from sperm trout, is used in therapy to stimulate tissue repair (43). It acts as an agonist on adenosine $\mathrm{A} 2 \mathrm{~A}$ receptors, stimulating VEGF production during pathological conditions of low tissue perfusion, including limb ischemia, varicocele, diabetes mellitus and thermal injury (43-46). It has been demonstrated that PDRN has potent anti-apoptotic activity, decreasing histological damage and ameliorating spermatogenic activity (47).

Vitamin E and Raxofelast. Vitamin E and its analogue raxofelast have potent antioxidant activity (11). Their administration results in a significant decrease in extracellular signal-regulated kinases 1/2 and c-Jun N-terminal kinase activation, reducing lipid peroxidation and protecting the testes from tIR (11).

\section{Calcium channel blockers}

Verapamil, Lidocaine, Nifedipine, Amlodipine. During I/R, damage occurs due to accumulation of intercellular $\mathrm{Ca}^{2+}$ and free radicals (48). The $\mathrm{Ca}^{2+} / \mathrm{Na}^{+}$channel blockers verapamil, lidocaine and nifedipine ameliorate the effect of I/R (49-52). Recently, it was demonstrated that amlodipine decreases free radical levels and increases the levels antioxidants including SOD and GSH (14).

\section{Interaction with neutrophils}

Antagonist of E-selectin. E-selectin acts by tethering neutrophils and facilitating their slow rolling along endothelial cells $(53,54)$. Neutrophil recruitment to affected organs is one of the hallmarks of I/R injury and E-selectin serves a critical role in neutrophil recruitment to the testes following I/R and the resulting germ cell-specific apoptosis (55). Blocking E-selectin with function-blocking monoclonal E-selectin antibody, even after the onset of reperfusion inhibits neutrophil recruitment to the I/R-induced murine testes. Blockade of E-selectin may therefore be a potential strategy to protect post-ischaemic testes and prevent infertility (54).

Sivelestat sodium aminoacetate tetrahydrate and taurine. Sivelestat sodium aminoacetate tetrahydrate is a synthetic, specific, low-molecular weight neutrophil elastase inhibitor (56). It has been demonstrated that sivelestat and taurine inhibit neutrophil elastase, which seems to serve a substantial role in
tIR injury by releasing toxic mediators such as oxygen-free radicals, that initiate a chain reaction leading to damage of the cell membrane (57). In this way, these molecules may offer efficient protection against testicular reperfusion injury (56-58).

\section{Interaction with renin-angiotensin system (RAS)}

Bosenta, Losartan, Enalapril, Zofenopril. In the testes, it has been reported that a local RAS is responsible for maintaining blood pressure and volume (59). During tIR injury, inhibition of the classical RAS pathway leads to reductions in testicular injury, inflammation and oxidative stress $(10,60)$. Recently, the testicular angiotenis converting enzyme (tACE)/Ang-(1-7)/Mas receptor axis has been described and it has been suggested that Ang-(1-7)-mediated protection may increase nitric oxide (NO) bioavailability, inhibit ROS generation and suppress apoptosis in tIR (10). Furthermore, it has been documented that bosentan, a dual endothelin receptor antagonist, has more beneficial effects than losartan, an angiotensin II type I antagonist and the ACE inhibitors enalapril and zofenopril in tIR injury (60).

\section{Modulators of inflammation}

Interleukin (IL)-10. IL-10 is a type of T Helper 2 type cytokine that modulates inflammatory responses by inhibiting the production of pro-inflammatory cytokines, including tumour necrosis factor (TNF)- $\alpha$, IL-1, IL-6, and IL-8 (61). Furthermore, IL-10 upregulates monocyte production of soluble TNF- $\alpha$ and IL-1 receptor antagonist (62). IL-10 appears to attenuate the damage in testes caused by tRI, due to its anti-inflammatory and antioxidant properties (62). It has been suggested that IL-10 may act by inhibiting the effects of ROS, thus reducing the levels of lipid peroxidation and myeloperoxidase and increasing GPx levels (62).

Melanocortins (MC). MCs are bioactive peptides derived from the cleavage of proopiomelanocortin and activate the motor arm of the vagal reflex by stimulating brain $\mathrm{MC}_{3}$ and $\mathrm{MC}_{4}$ receptors. In this way, they blunt the inflammatory cascade and the apoptotic reaction and exert strong protection against ischemia in a number of experimental models (63). The selective $\mathrm{MC}_{4}$ receptor antagonist HS024 activates the cholinergic anti-inflammatory pathway that projects towards the testes, and thus is responsible for the beneficial effects of MCs against tIR injury (63).

Metformin. Metformin, typically used to manage type II diabetes, may serve a role in alleviating inflammatory responses, which is beneficial in protecting the testes from tIR injury (64).

Pyrrolidine dithiocarbamate (PDTC). PDTC is a specific inhibitor of nuclear factor $(\mathrm{NF}) \kappa \mathrm{B}$, a protein complex associated with immune responses, inflammatory processes, cellular proliferation and apoptosis (65). Activation of NFאB by IL-1, TNF- $\alpha$ and lipopolysaccharides is blocked by administration of PDTC. Results from an experimental study demonstrated that PDTC has beneficial effects against tIR injury by lowering MDA levels and increasing SOD activity, as well as reducing the number of apoptotic cells (66). 
Montelukast. Montelukast is an antioxidant that is also a selective antagonist of cysteinyl leukotriene receptor 1 and is used as an anti-asthmatic drug in clinical settings (67). It protects testes against I/R by inhibiting neutrophil activity, decreasing inducible nitric oxide synthase (iNOS) levels and attenuating apoptosis (68).

\section{Physical therapies}

Hyperbaric oxygen $(\mathrm{HBO})$. HBO therapy, through plasma oxygen transport, is currently used as an alternative treatment for ischemic tissues including brain, heart, liver, kidney, lung, skeletal muscle, and intestinal tissue $(69,70)$. HBO therapy attenuates tIR-induced injury by blocking oxidative stress, suppressing inflammation, and reducing NO formation (69). Furthermore, HBO therapy reduces dimethylarginine dimethylaminohydrolase activity and asymmetric dimethylarginine content, which may contribute to a reduction of NO formation in tIR (69).

Hypothermia. Hypothermia treatment, which involves placing the testicle in ice slush during ischemia and maintaining a surface temperature of $2-4^{\circ} \mathrm{C}$, reduces histological damage in a rat model of tIR (71).

Ischemic post-conditioning. Ischemic post-conditioning is an innovative surgical technique against reperfusion injury, defined as rapid intermittent interruptions of blood flow at the early phase of reperfusion. Ischemic post-conditioning mechanically alters hydrodynamics of reperfusion and has been demonstrated to have an early beneficial effect in tIR (72). However, its role against late damage in tIR remains controversial (73).

\section{Phytotherapeutics}

Apocynin. Apocynin (4-hydroxy-3methoxy-acetophenone) is a naturally occurring methoxysubstituted catechol, extracted from the roots of Apocynumcannabinum (Canadian hemp) and Picrorhiza kurroa (Scrophulariaceae), and is a known inhibitor of NADPH-oxidase (74), which is considered to be an important source of ROS and reactive nitrogen species (RNS). In this way, apocynin depresses the generation of toxic reactive metabolites, restoring levels of antioxidant GSH and inhibiting oxidative stress-associated tissue neutrophil accumulation induced by tIR (75).

Caffeic acid phenethyl ester (CAPE). The administration of CAPE inhibits increases in iNOS and myeloperoxidase, and it has been suggested that CAPE may inhibit neutrophil mediated cellular injury (76).

3',4'-dihydroxyflavonol. 3',4'-dihydroxyflavonol may exert a protective effect against lipid peroxidation in experimental I/R injury by both inhibiting oxidants and strengthening the action of antioxidants (77).

Epigallocatechin-3-gallate (EGCG). EGCG, one of the primary components of polyphenols in green tea, has been widely investigated as it suppresses the inflammatory processes that lead to transformation, inhibits cell proliferation and exerts strong antiradical activity (78-80). EGCG is used as a nutritional supplement due to its many health benefits and it has been demonstrated to protect against I/R-induced apoptosis in vitro and in vivo (80). An adjunct interventional use of EGCG prior to testicular detorsion surgery may prevent the destructive effects of tIR injury (78).

Genistein. Genistein is an isoflavone extracted from soy that has been demonstrated to protect the testes via attenuation of oxidative stress and inhibition of the caspase- 8 apoptosis pathway (81).

Ginkgo biloba. Extract of Ginkgo biloba leaves has antioxidant properties as a free-radical scavenger (82). It contains flavone glycosides (primarily quercetin, kaempferol and isorhamnetin), terpene lactones (2.8-3.4\% ginkgolides A, B and $\mathrm{C}$, and 2.6-3.2\% bilobalide), ginkgolide B, bilobalide, proanthocyanadins, glucose, rhamnose, organic acids, D-glucaric acid and ginkgolic acid (82). Ginkgo biloba leaves promote vasodilation and improve blood flow through arteries, veins and capillaries. They inhibit platelet aggregation and prolong bleeding time. Therefore, administration of the Ginkgo biloba leaves extract offers potential protection against tIR injury (82).

Goji berry. Goji berry is a herb from the Solanaceae family that also has reported antioxidant effects. Experimental studies have demonstrated that goji berry reduces blood sugar and lipid levels, and exhibits anti-ageing, immuno-modulating, antitumour, anti-fatigue and male fertility-enhancing effects (83). Goji berry extracts seem to reduce tIR injury via their antioxidant effects in testes torsion (83).

Lycopene. Lycopene is a red carotenoid found in large amounts in tomatoes. A number of studies support that lycopene, rather than $\beta$-carotene, is a precursor of vitamin $\mathrm{A}(84,85)$. It has been proposed as a useful molecule for different types of cancer, coronary artery disease, bone health, male fertility, hypertension and neurodegenerative diseases $(39,85)$. Lycopene is an effective antioxidant and may protect against the negative effects of tIR when used in the early phase of testicular torsion (85).

Psoralea corylifolia. Psoralea corylifolia is a widely used traditional Chinese medicine, extracted from mature and dry fruits of Leguminous plant Psoralea corylifolia. It has been officially listed in the Pharmacopoeia of the People's Republic of China $(86,87)$ and is used to treat male reproductive dysfunctions, such as premature ejaculation, impotence and spermatorrhea. The constituents of Psoralea corylifolia include coumarins, flavonoids and meroterpenes, such as psoralen, isopsoralen, bavachinin, bavachin, psoralidin, neobavaisoflavone and bavachalcone (86). Psoralea corylifolia may exert a protective effect against tIR injury, as it exhibits scavenging activity against ROS (87).

Quercetin. Quercetin is a major flavonol in the diet and its primary dietary sources are tea, onions, apples and red wine (88). Quercetin has been found to possess antilipoperoxidant, 
antiplatelet and anti-inflammatory activities and inhibits the enzymic activities of lipooxygenase, xanthine oxidase and cyclooxygenase (88). Quercetin is considered to be the most potent scavenger of ROS, such as superoxide and RNS, such as NO, and seems to alleviate ischemia and reperfusion injury in rat testes (88).

Resveratrol (RSV). RSV (trans-3,5,4'-tri-hydroxystilbene) is a natural phytoalexin with antioxidant properties. RSV is found in many plants, including berries, grapes and peanuts, and it protects the cell by preventing lipid peroxidation in the cell membrane and preventing DNA damage caused by excessive ROS production (89). It has been reported that RSV treatment has a positive effect in balancing the oxidant/antioxidant equilibrium, thus reducing the apoptotic rate in an experimental tIR model (89).

Rutin. Rutin is a flavone glycoside that is abundant in a wide variety of plants. It possesses several physiological properties, including antioxidant, anti-inflammatory and anticancer activities $(90,91)$. Rutin ameliorates tIR by scavenging ROS and increasing the activity of SOD and CAT (92).

Ternatin (TTN). TTN, a tetramoxyflavone extracted from Egletes viscosa L., has protective effects against the testes tissue lipid peroxidation injury and oxidative stress that results in tIR (93).

Thymoquinone (TQ). TQ is the primary bioactive constituent of Nigella sativa seed oil. TQ has diverse pharmacological properties, including antidiabetic, analgesic and anti-inflammatory properties, and is considered to be a very strong antioxidant (94-96). In Turkey, India, Arabia and many Middle Eastern countries, there is a belief that 'regular use of Black Seed can cure anything, except death'. It is thus suggested that TQ may have protective effects in tIR injury $(97,98)$.

\section{Platelet inhibitors}

Dipyridamole and acetylsalicylic acid (ASA). Dipyridamole and ASA possess antioxidant properties. Dipyridamole is an adenosine transporter inhibitor that inhibits cellular adenosine reuptake and increases interstitial adenosine concentration by inhibiting the activity of caspase, thus inhibiting apoptosis. $(99,100)$. Dipyridamole blocks the activity of caspases, which serve a major role during apoptotic cell death. ASA suppresses platelet aggregation by inhibiting thromboxane A2 production and subsequently blocking the arachidonate cascade. It has also been demonstrated that ASA exhibits free radical-scavenging properties, thus protecting endothelial cells against the negative effects of hydrogen peroxide (101).

In a study comparing the potential protective effects of dipyridamole and ASA in a rat model of tIR, it was observed that a significant decrease in apoptotic index in tIR injury in the dipyridamole group (99).

\section{Sex steroid precursors}

Dehydroepiandrosterone. It remains unclear whether dehydroepiandrosterone exerts its effects directly or does so following its conversion to androgens or estrogens. Inserting DHEA into the lipid membranes may make them more resistant to oxidative stress, thus protecting the testes against tIR injury (9).

\section{Vasodilator agents}

Carvedilol (CVD). CVD [1-[carbazolyl-(4)-oxy]-3-[(2methoxyphenoxyethl) amino]-2-propanol] is a third-generation vasodilator agent used in the treatment of hypertension, ischemic heart disease and congestive heart failure (102-104). It selectively blocks $\alpha 1$-receptors and non-selectively blocks $\beta 1$ and $\beta 2$-adrenoceptors (102). CVD and some of its metabolites also exhibit antioxidant activity. Following CVD administration in an experimental model of tIR injury, levels of malondialdehyde decrease to a level similar to a sham group (105).

Sildenafil and udenafil. Sildenafil increases the activity of antioxidant enzymes and decreases MDA levels following tIR injury in rats (106). Sildenafil may inhibit the production of lipid peroxidation by inhibiting the activity and expression of nicotinamide adenine dinucleotide phosphate (NADPH) oxidase (106). Udenafil citrate also acts in a similar fashion to protect the testes from tIR injury (107).

Trapidil. Trapidil (5-methyl-7-diethylamino-s-triazolopyrimidine), originally used as an anti-anginal drug, is a phosphodiesterase and platelet derived growth factor inhibitor (108). It decreases free oxygen radical formation in tIR and attenuates histopathological damage in ipsilateral twisted testes (109).

\section{Other mechanisms}

Rosiglitazone. Rosiglitazone is the most potent and selective peroxisome proliferator-activated receptor-gamma (PPAR-g) ligand. PPAR-g is a member of the nuclear hormone receptor superfamily involved in a number of physiological processes, including atherosclerosis, inflammation, cancer, infertility and demyelination (110). It has been demonstrated that rosiglitazone prevents cell injury by increasing endothelial NOS expression in the contralateral testicular tissue in a model of tIR (110).

\section{Conclusions}

By reviewing the current literature, it seems that a number of medications, experimentally and sometimes clinically, serve an adjuvant role in cellular damage following ischemia-reperfusion. Testicular torsion in animals represents a practical model of ischemia-reperfusion in humans.

A number of experimental studies have been published regarding the use of different types medication and their role in decreasing cellular damage following reperfusion. Since the primary causes of testicular damage are represented by ROS production, an increase in the levels of intra-mitochondrial calcium and an increased rate of cellular apoptosis, different types of medication have been proposed as potentially useful.

Antioxidants, calcium channel blockers, phytotherapeutics, anaesthetics, hormones and platelet inhibitors may 
potentially create a solid bases for an adjuvant restoring therapy and ameliorate testicular function following torsion. However, currently, the immediate restoration of blood flow is the primary therapeutic approach to treat torsion of the spermatic cord. In order to avoid or reduce the rate of reperfusion injury, future multicentric randomized controlled trials are warranted. These may provide further insight into the actions of the aforementioned molecules and their precise roles.

\section{References}

1. Unsal A, Devrim E, Guven C, Eroglu M, Durak I, Bozoklu A and Balbay MD: Propofol attenuates reperfusion injury after testicular torsion and detorsion. World J Urol 22: 461-465, 2004.

2. Ringdahl E and Teague L: Testicular torsion. Am Fam Physician 74: 1739-1743, 2006.

3. Tamamura M, Saito M, Kinoshita Y, Shimizu S, Satoh I, Shomori K, Dimitriadi F and Satoh K: Protective effect of edaravone, a free-radical scavenger, on ischaemia-reperfusion injury in the rat testis. BJU Int 105: 870-876, 2010.

4. Werns SW and Lucchesi BR: Free radicals and ischemic tissue injury. Trends Pharmacol Sci 11: 161-166, 1990.

5. Elshaari FA, Elfagih RI, Sheriff DS and Barassi IF: Oxidative and antioxidative defense system in testicular torsion/detorsion. Indian J Urol 27: 479-484, 2011.

6. Unsal A, Eroglu M, Avci A, Cimentepe E, Guven C, Derya Balbay M and Durak I: Protective role of natural antioxidant supplementation on testicular tissue after testicular torsion and detorsion. Scand J Urol Nephrol 40: 17-22, 2006.

7. Minutoli L, Antonuccio P, Polito F, Bitto A, Fiumara T, Squadrito F, Nicotina PA, Arena S, Marini H, Romeo C and Altavilla D: Involvement of mitogen-activated protein kinases (MAPKs) during testicular ischemia-reperfusion injury in nuclear factor-kappaB knock-out mice. Life Sci 81: 413-422, 2007.

8. Akbas H, Ozden M, Kanko M, Maral H, Bulbul S, Yavuz S, Ozker E and Berki T: Protective antioxidant effects of carvedilol in a rat model of ischaemia-reperfusion injury. J Int Med Res 33: 528-536, 2005

9. Aksoy H, Yapanoglu T, Aksoy Y, Ozbey I, Turhan H and Gursan N: Dehydroepiandrosterone treatment attenuates reperfusion injury after testicular torsion and detorsion in rats. J Pediatr Surg 42: 1740-1744, 2007.

10. Al-Maghrebi M and Renno WM: The tACE/angiotensin(1-7)/mas axis protects against testicular ischemia reperfusion injury. Urology 94: 312. e1-8, 2016.

11. Antonuccio P, Minutoli L, Romeo C, Nicòtina PA, Bitto A, Arena S, Altavilla D, Zuccarello B, Polito F and Squadrito F: Lipid peroxidation activates mitogen-activated protein kinases in testicular ischemia-reperfusion injury. J Urol 176: 1666-1672, 2006.

12. Minutoli L, Antonuccio P, Romeo C, Nicòtina PA, Bitto A, Arena S, Polito F, Altavilla D, Turiaco N, Cutrupi A, et al: Evidence for a role of mitogen-activated protein kinase 3/mitogen-activated protein kinase in the development of testicular ischemia-reperfusion injury. Biol Reprod 73: 730-736, 2005.

13. Minutoli L, Antonuccio P, Polito F, Bitto A, Squadrito F, Di Stefano V, Nicotina PA, Fazzari C, Maisano D, Romeo C and Altavilla D: Mitogen-activated protein kinase 3/mitogen-activated protein kinase 1 activates apoptosis during testicular ischemia-reperfusion injury in a nuclear factor-kappaB-independent manner. Eur J Pharmacol 604: 27-35, 2009.

14. Dogan C, Halici Z, Topcu A, Cadirci E, Karakus E, Bayir Y and Selli J: Effects of amlodipine on ischaemia/reperfusion injury in the rat testis. Andrologia 48: 441-452, 2016.

15. Trocha M and Szelag A: The role of calcium and calcium channel blocking drugs in damage to the liver preserved for transplantation. Ann Transplant 9: 5-11, 2004.

16. Vercesi AE, Kowaltowski AJ, Oliveira HC and Castilho RF: Mitochondrial $\mathrm{Ca} 2+$ transport, permeability transition and oxidative stress in cell death: Implications in cardiotoxicity, neurodegeneration and dyslipidemias. Front Biosci 11: 2554-2564, 2006.

17. Nicoud IB, Knox CD, Jones CM, Anderson CD, Pierce JM, Belous AE, Earl TM and Chari RS: 2-APB protects against liver ischemia-reperfusion injury by reducing cellular and mitochondrial calcium uptake. Am J Physiol Gastrointest Liver Physiol 293: G623-G630, 2007.
18. Kapoor S: Testicular torsion: A race against time. Int J Clin Pract 62: 821-827, 2008.

19. Grasso G, Meli F, Fodale V, Calapai G, Buemi M and Iacopino DG: Neuroprotective potential of erythropoietin and darbepoetin alfa in an experimental model of sciatic nerve injury. Laboratory investigation. J Neurosurg Spine 7: 645-651, 2007.

20. Akcora B, Altug ME, Kontas T and Atik E: The protective effect of darbepoetin alfa on experimental testicular torsion and detorsion injury. Int J Urol 14: 846-850, 2007.

21. Ergur BU, Kiray M, Pekcetin C, Bagriyanik HA and Erbil G: Protective effect of erythropoietin pretreatment in testicular ischemia-reperfusion injury in rats. J Pediatr Surg 43: 722-728, 2008.

22. Hanci V, Erol B, Bektas S, Mungan G, Yurtlu S, Tokgöz H, Can M and Ozkoçak Turan I: Effect of Dexmedetomidine on testicular torsion/detorsion damage in rats. Urol Int 84: 105-111, 2010.

23. Tuglu D, Yuvanc E, Yilmaz E, Gencay IY, Atasoy P, Kisa U and Batislam E: The antioxidant effect of dexmedetomidine on testicular ischemia-reperfusion injury. Acta Cir Bras 30: 414-421, 2015.

24. Schultz JE, Hsu AK and Gross GJ: Morphine mimics the cardioprotective effect of ischemic preconditioning via a glibenclamide-sensitive mechanism in the rat heart. Circ Res 78: 1100-1104, 1996.

25. Błaszczyk J, Kedziora J, Luciak M, Sibińska E, Trznadel K and Pawlicki L: Effect of morphine and naloxone on oxidative metabolism during experimental renal ischemia and reperfusion. Exp Nephrol 2: 364-370, 1994.

26. Salmasi AH, Beheshtian A, Payabvash S, Demehri S, Ebrahimkhani MR, Karimzadegan M, Bahadori M, Pasalar P and Dehpour AR: Effect of morphine on ischemia-reperfusion injury: Experimental study in testicular torsion rat model. Urology 66: 1338-1342, 2005.

27. Urt Filho A, Inouye CM, Pontes JC, Silva AC, Silva GV and Santos CH: Propofol effects on the morphology of rat testes subjected to testicular ischemia-reperfusion. Acta Cir Bras 27: $172-178,2012$.

28. Ozbal S, Ergur BU, Erbil G, Tekmen I, Bagrıyanık A and Cavdar Z: The effects of $\alpha$-lipoic acid against testicular ischemia-reperfusion injury in Rats. Scientific World Journal 2012: 489248, 2012.

29. Guimarães SB, Kimura OS and Vasconcelos PR: Dimethylsulfoxide attenuates ischemia-reperfusion injury in rat testis. Acta Cir Bras 25: 357-361, 2010.

30. Saluk J, Bijak M, Nowak P and Wachowicz B: Evaluating the antioxidative activity of diselenide containing compounds in human blood. Bioorg Chem 50: 26-33, 2013.

31. Rifaioglu MM, Motor S, Davarci I, Tuzcu K, Sefil F, Davarci M and Nacar A: Protective effect of ebselen on experimental testicular torsion and detorsion injury. Andrologia 46: 1134-1340, 2014.

32. Shah DM, Powers SR Jr, Stratton HH and Newell JC: Effects of hypertonic mannitol on oxygen utilization in canine hind limbs following shock. J Surg Res 30: 593-601, 1981.

33. Kurt O, Yazici CM, Erboga M, Turan C, Bozdemir Y, Akbas A, Turker P, Aktas C, Aydin M and Yesildag E: Mannitol has a protective effect on testicular torsion: An experimental rat model. J Pediatr Urol 12: 167. e1-8, 2016.

34. Prillaman HM and Turner TT: Rescue of testicular function after acute experimental torsion. J Urol 157: 340-345, 1997.

35. Rodriguez C, Mayo JC, Sainz RM, Antolín I, Herrera F, Martín V and Reiter RJ: Regulation of antioxidant enzymes: A significant role for melatonin. J Pineal Res 36: 1-9, 2004.

36. Ekici S, Doğan Ekici AI, Öztürk G, Benli Aksungar F, Sinanoğlu O, Turan G and Lüleci N: Comparison of melatonin and ozone in the prevention of reperfusion injury following unilateral testicular torsion in rats. Urology 80: 899-906, 2012.

37. Parlaktas BS, Atilgan D, Ozyurt H, Gencten Y, Akbas A, Erdemir F and Uluocak N: The biochemical effects of ischemia-reperfusion injury in the ipsilateral and contralateral testes of rats and the protective role of melatonin. Asian J Androl 16: 314-318, 2014.

38. Minutoli L, Altavilla D, Marini H, Rinaldi M, Irrera N, Pizzino G, Bitto A, Arena S, Cimino S, Squadrito F, et al: Inhibitors of apoptosis proteins in experimental benign prostatic hyperplasia: Effects of serenoa repens, selenium and lycopene. J Biomed Sci 21: 19, 2014.

39. Altavilla D, Bitto A, Polito F, Irrera N, Marini H, Arena S, Favilla V, Squadrito F, Morgia G and Minutoli L: The combination of Serenoa repens, selenium and lycopene is more effective than serenoa repens alone to prevent hormone dependent prostatic growth. J Urol 186: 1524-1529, 2011. 
40. Kara Ö, Sari E, Aksit H, Yay A, Aksit D and Dönmez MI: Effects of selenium on ischaemia-reperfusion injury in a rat testis model. Andrologia 48: 1267-1273, 2016.

41. Tu YP, Chuang SJ, Chen SC, Liu YH, Chen CF and Hour TC: Simvastatin induces the expression of hemeoxygenase-1 agains ischemia-reperfusion injury on the testes in rats. Toxicol Lett 207: 242-250, 2011.

42. Karakaya E, Ates O, Akgür FM and Olguner M: Rosuvastatin protects tissue perfusion in the experimental testicular torsion model. Int Urol Nephrol 42: 357-360, 2010.

43. Minutoli L, Arena S, Antonuccio P, Romeo C, Bitto A, Magno C, Rinaldi M, Micali A, Irrera N, Pizzino G, et al: Role of inhibitors of apoptosis proteins in testicular function and male fertility: Effects of polydeoxyribonucleotide administration in experimental varicocele. Biomed Res Int 2015: 248976 , 2015.

44. Arena S, Minutoli L, Arena F, Nicotina PA, Romeo C, Squadrito F, Altavilla D, Morgia G and Magno C: Polydeoxyribonucleotide administration improves the intra-testicular vascularization in rat experimental varicocele. Fertil Steril 97: 165-168, 2012.

45. Arena $\mathrm{S}$ and Romeo C: The intriguing role of VEGF in varicocele. Andrologia.

46. Minutoli L, Arena S, Bonvissuto G, Bitto A, Polito F, Irrera N, Arena F, Fragalà E, Romeo C, Nicotina PA, et al: Activation of adenosine A2A receptors by polydeoxyribonucleotide increases vascular endothelial growth factor and protects against testicular damage induced by experimental varicocele in rats. Fertil Steril 95: 1510-1513, 2011.

47. Minutoli L, Antonuccio P, Squadrito F, Bitto A, Nicotina PA, Fazzari C, Polito F, Marini H, Bonvissuto G, Arena S, et al: Effects of polydeoxyribonucleotide on the histological damage and the altered spermatogenesis induced by testicular ischaemia and reperfusion in rats. Int J Androl 35: 133-144, 2012.

48. Dusmez D, Cengiz B, Yumrutas O, Demir T, Oztuzcu S, Demiryurek S, Tutar E, Bayraktar R, Bulut A, Simsek H, et al: Effect of verapamil and lidocaine on TRPM and NaV1.9 gene expressions in renal ischemia-reperfusion. Transplant Proc 46 33-39, 2014.

49. Uchida M, Takemoto Y, Nagasue N, Dhar DK, Kohno H and Nakamura T: Effect of verapamil on hepatic reperfusion injury after prolonged ischemia in pigs. J Hepatol 21: 217-223, 1994

50. Eskitascioglu T, Karaci S, Canoz O, K1lıc E and Gunay GK: The impact of lidocaine on flap survival following reperfusion injury. J Surg Res 167: 323-328, 2011

51. Popp SS, Lei B, Kelemen E, Fenton AA, Cottrell JE and Kass IS Intravenous antiarrhythmic doses of lidocaine increase the survival rate of CA1 neurons and improve cognitive outcome after transient global cerebral ischemia in rats. Neuroscience 192 537-549, 2011.

52. Meštrović J, Drmić-Hofman I, Pogorelić Z, Vilović K, Šupe-Domić D, Šešelja-Perišin A and Capkun V: Beneficial effect of nifedipine on testicular torsion-detorsion injury in rats. Urology 84: 1194-1198, 2014.

53. Kunkel EJ and Ley K: Distinct phenotype of E-selectin-deficient mice. E-selectin is required for slow leukocyte rolling in vivo. Circ Res 79: 1196-1204, 1996.

54. Celebi M and Paul AG: Blocking E-selectin inhibits ischaemia-reperfusion-induced neutrophil recruitment to the murine testis. Andrologia 40: 235-239, 2008.

55. Lysiak JJ, Turner SD, Nguyen QA, Singbartl K, Ley K and Turner TT: Essential role of neutrophils in germ cell-specific apoptosis following ischemia/reperfusion injury of the mouse testis. Biol Reprod 65: 718-725, 2001.

56. Yoshikawa N, Inomata T, Okada Y, Shimbo T, Takahashi M, Akita K, Uesugi Y and Narumi Y: Sivelestat sodium hydrate reduces radiation-induced lung injury in mice by inhibiting neutrophil elastase. Mol Med Rep 7: 1091-1105, 2013.

57. Tsounapi P, Saito M, Dimitriadis F, Shimizu S, Kinoshita Y, Shomori K, Satoh I and Satoh K: Protective effect of sivelestat, a neutrophil elastase inhibitor, on ipsilateral and contralateral testes after unilateral testicular ischaemia-reperfusion injury in rats. BJU Int 107: 329-336, 2011

58. Wei SM, Yan ZZ and Zhou J: Taurine reduces testicular ischemia/reperfusion-induced neutrophil recruitment to testis probably by downregulation of pro-inflammatory cytokines and E-selectin. Urology 72: 464-465, 2008.

59. Leung PS and Sernia C: The renin-angiotensin system and male reproduction: New functions for old hormones. J Mol Endocrinol 30: 263-270,2003.
60. Turkili B, Kurcer Z, Dengiz GO, Kandemir NO, Mungan G, Ozacmak VH and Banoglu ZN: Role of angiotensin and endothelin in testicular ischemia reperfusion injury. Int J Urol 19: 257-263, 2012

61. Cassatella MA, Meda L, Bonora S, Ceska M and Constantin G: Interleukin 10 (IL-10) inhibits the release of proinflammatory cytokines from human polymorphonuclear leukocytes. Evidence for an autocrine role of tumor necrosis factor and IL-1 beta in mediating the production of IL-8 triggered by lipopolysaccharide. J Exp Med 178: 2207-2211, 1993 .

62. Ozturk H, Ozturk H, Terzi EH, Bugdayci G and Duran A: Interleukin 10 reduces testicular damage in experimental testicular ischemia/reperfusion injury. Urology 83: 508. e1-6, 2014.

63. Minutoli L, Bitto A, Squadrito F, Irrera N, Rinaldi M, Nicotina PA, Arena S, Magno C, Marini H, Spaccapelo L, et al: Melanocortin 4 receptor activation protects against testicular ischemia-reperfusion injury by triggering the cholinergic antiinflammatory pathway. Endocrinology 152: 3852-3861, 2011.

64. Asghari A, Akbari G, Meghdadi A and Mortazavi P: Protective effect of metformin on testicular ischemia/reperfusion injury in rats. Acta Cir Bras 31: 411-416, 2016.

65. Ahn KS, Sethi G and Aggarwal BB: Nuclear factor-kappa B: From clone to clinic. Curr Mol Med 7: 619-637, 2007.

66. Kemahli E, Yildiz M, Firat T, Özyalvaçli ME, Üyetürk U, Yilmaz B and Gücük A: An experimental study on effects of pyrrolidine dithiocarbamate on ischemia-reperfusion injury in testis. Can Urol Assoc J 10: E104-E109, 2016.

67. Sener G, Sehirli O, Velioğlu-Oğünç A, Cetinel S, Gedik N, Caner M, Sakarcan A and Yeğen BC: Montelukast protects against renal ischemia/reperfusion injury in rats. Pharmacol Res 54: 65-71, 2006.

68. Sılay MS, Toklu H, Özağarı A, Aydın M, Tetik Ş, Şener G, Miroğlu $\mathrm{C}$ and Kendirci M: Montelukast prevents testes against ischemia-reperfusion injury through suppression of iNOS expression. Turk J Urol 40: 221-227, 2014.

69. Zhang Y, Lv Y, Liu YJ, Yang C, Hu HJ, Meng XE, Li MX and Pan SY: Hyperbaric oxygen therapy in rats attenuates ischemia-reperfusion testicular injury through blockade of oxidative stress, suppression of inflammation, and reduction of nitric oxide formation. Urology 82: 489.e9-489.e15, 2013.

70. Thom SR: Hyperbaric oxygen: Its mechanisms and efficacy. Plast Reconstr Surg 127 (Suppl 1): S131-S141, 2011

71. Almodhen F, He X, Loutochin O, Jednak R, Capolicchio JP and El-Sherbiny MT: Protective role of hypothermia on ischemia of prepubertal rodent testicle. Urology 77: 762.e8-12, 2011.

72. Ozkisacik S, Erdem AO, Durmaz O, Culhaci N, Gursoy H and Yazici M: The long-term protective effects of short-interval postconditioning in testicular ischemia-reperfusion injury in rats. J Pediatr Surg 47: 743-746, 2012.

73. Minutoli L, Irrera N, Squadrito F, Marini H, Nicotina PA, Arena S, Romeo C, Antonuccio P and Altavilla D: Effects of ischaemic post-conditioning on the early and late testicular damage after experimental testis ischaemia-reperfusion. Andrology 2: 76-582, 2014.

74. Stefanska J and Pawliczak R: Apocynin: Molecular aptitudes. Mediators Inflamm 2008: 106507, 2008.

75. SSener TE, Yüksel M, Özyılmaz-Yay N, Ercan F, Akbal C, Şimşek F and Şener G: Apocynin attenuates testicular ischemia-reperfusion injury in rats. J Pediatr Surg 50: 1382-1387, 2015.

76. Atik E, Görür S and Kiper AN: The effect of caffeic acid phenethyl ester (CAPE) on histopathological changes in testicular ischemia-reperfusion injury. Pharmacol Res 54: 293-297, 2006.

77. Duman A, Mogulkoc R, Baltaci AK and Menevse E: 3', 4'-dihydroxyflavonol attenuates tissue damage in unilateral testis ischemia-reperfusion in rats. Bratisl Lek Listy 116: 735-740, 2015.

78. Al-Maghrebi M, Renno WM and Al-Ajmi N: Epigallocatechin-3gallate inhibits apoptosis and protects testicular seminiferous tubules from ischemia/reperfusion-induced inflammation. Biochem Biophys Res Commun 420: 434-439, 2012.

79. Higdon JV and Frei B: Tea catechins and polyphenols: Health effects, metabolism, and antioxidant functions. Crit Rev Food Sci Nutr 43: 89-143, 2003.

80. Singh BN, Shankar S and Srivastava RK: Green tea catechin, epigallocatechin-3-gallate (EGCG): Mechanisms, perspectives and clinical applications. Biochem Pharmacol 82: 1807-1821, 2011. 
81. Al-Maghrebi M and Renno WM: Genistein alleviates testicular ischemia and reperfusion injury-induced spermatogenic damage and oxidative stress by suppressing abnormal testicular matrix metalloproteinase system via the Notch $2 /$ Jagged $1 /$ Hes-1 and caspase-8 pathways. J Physiol Pharmacol 67: 129-137, 2016.

82. Kanter M: Protective effects of Ginkgo biloba (EGb 761) on testicular torsion/detorsion-induced ischemia-reperfusion injury in rats. Exp Mol Pathol 91: 708-713, 2011.

83. Dursun R, Zengin Y, Gündüz E, İçer M, Durgun HM, Dağgulli M, Kaplan I, Alabalık U and Güloğlu C: The protective effect of goji berry extract in ischemic reperfusion in testis torsion. Int J Clin Exp Med 8: 2727-2733, 2015.

84. Bramley PM: Is lycopene beneficial to human health? Phytochemistry 54: 233-236, 2000.

85. Güzel M, Sönmez MF, Baştuğ O, Aras NF, Öztürk AB, Küçükaydın M and Turan C: Effectiveness of lycopene on experimental testicular torsion. J Pediatr Surg 51: 1187-1191, 2016.

86. Wei SM, Yan ZZ and Zhou J: Psoralea corylifolia protects against testicular torsion/detorsion-induced ischemia/reperfusion injury. J Ethnopharmacol 137: 568-574, 2011.

87. Zhao LH, Wu MH and Xiang BR: Analysis of Psoralea corylifolia L. fruits indifferent regions. Chem Pharm Bull (Tokyo) 53: 1054-1057, 2005.

88. Aldemir M, Özgün G, Önen E, Okulu E and Kayıgil Ö: Quercetin has a protectiverole on histopathological findings on testicular ischaemia-reperfusion injury in rats. Andrologia 44 (Suppl 1): S479-S483, 2012.

89. Yuluğ E, Türedi S, Karagüzel E, Kutlu O, Mentese A and Alver A: The short term effects of resveratrol on ischemia-reperfusion injury in rat testis. J Pediatr Surg 49: 484-499, 2014.

90. La Casa C, Villegas I, Alarcón de la Lastra C, Motilva V and Martín Calero MJ: Evidence for protective and antioxidant properties of rutin, a natural flavone, against ethanol induced gastric lesions. J Ethnopharmacol 71: 45-53, 2000.

91. Shen SC, Ko CH, Tseng SW, Tsai SH and Chen YC: Structurally related antitumor effects of flavanones in vitro and in vivo: Involvement of caspase 3 activation, p21 gene expression, and reactive oxygen species production. Toxicol Appl Pharmacol 197: $84-95,2004$

92. Wei SM, Yan ZZ and Zhou J: Protective effect of rutin on testicular ischemia-reperfusion injury. J Pediatr Surg 46: 1419-1424, 2011.

93. Guimarães SB, Santos JM, Aragão AA, Kimura OS, Silveira ER and Vasconcelos PR: Ternatin pretreatment attenuates testicular injury induced by torsion/detorsion in Wistar rats. Acta Cir Bras 26: 325-328, 2011.

94. Burits $\mathrm{M}$ and Bucar F: Antioxidant activity of Nigella sativa essential oil. Phytother Res 14: 323-328, 2000.

95. Gilhotra $\mathrm{N}$ and Dhingra D: Thymoquinone produced antianxiety-like effects in mice through modulation of GABA and NO levels. Pharmacol Rep 63: 660-669, 2011.

96. Sankaranarayanan $C$ and Pari L: Thymoquinone ameliorates chemical induced oxidative stress and $\beta$-cell damage in experimental hyperglycemic rats. Chem Biol Interact 190: 148-154, 2011.

97. Ayan M, Tas U, Sogut E, Caylı S, Kaya H, Esen M, Erdemir F and Uysal M: Protective effect of thymoquinone against testicular torsion induced oxidative injury. Andrologia 48: 143-151, 2016.
98. Sheikhbahaei F, Khazaei M, Rabzia A, Mansouri K and Ghanbari A: Protective effects of thymoquinone against methotrexate-induced germ cell apoptosis in male mice. Int J Fertil Steril 9: 541-557, 2016

99. Karagüzel E, Kutlu Ö, Yuluğ E, Mungan S, Kazaz İO, Tok DS and Ozgür GK: Comparison of the protective effect of dipyridamole and acetylsalicylic acid on long-term histologic damage in a rat model of testicular ischemia-reperfusion injury. J Pediatr Surg 47: 1716-1723, 2012.

100. Yang D, YaguchiT,NakanoT and NishizakiT: Adenosine-induced caspase-3 activation by tuning Bcl-XL/DIABLO/IAP expression in HuH-7 human hepatoma cells. Cell Biol Toxicol 26: 319-330, 2010

101. Podhaisky HP, Abate A, Polte T, Oberle S and Schröder H: Aspirin protects endothelial cells from oxidative stress-possible synergism with vitamin E. FEBS Lett 417: 349-351, 1997

102. Özsoy AZ, Nursal AF, Arıcı A, Bütün İ, Uysal M, Irmak Sapmaz H, Kuntİşgüder Ç, Yılmaz Doğru H and Taş U: Effects of carvedilol on an ischemia/reperfusion model: Biochemical, histopathological and immunohistochemical evaluation. J Obstet Gynaecol Res 42: 1132-1140, 2016.

103. Hayashi T, De Velasco MA, Saitou Y, Nose K, Nishioka T, Ishii $\mathrm{T}$ and Uemura $\mathrm{H}$ : Carvedilol protects tubular epithelial cells from ischemia-reperfusion injury by inhibiting oxidative stress. Int J Urol 17: 989-995, 2010.

104. Hayashi T, Saitou Y, Nose K, Nishioka T, Ishii T and Uemura H: Efficacy of carvedilol for ischemia/reperfusion-induced oxidative renal injury in rats. Transplant Proc 40: 2139-2141, 2008 .

105. Parlaktas BS, Atilgan D, Gencten Y, Akbas A, Markoc F, Erdemir F, Ozyurt $\mathrm{H}$ and Uluocak N: The effects of carvedilol on ischemia-reperfusion injury in the rat testis. Int Braz J Urol 40: 109-117, 2014.

106. Yildiz H, Durmuş AS, Şimşek H and Yaman İ: Effects of sildenafil citrate on torsion/detorsion-induced changes in red blood cell and plasma lipid peroxidation, antioxidants, and blood hematology of male rats. Eur J Obstet Gynecol Reprod Biol 159: 359-363, 2011.

107. Tuglu D, Yuvanc E, Ozan T, Bal F, Yilmaz E, Atasoy P, Kisa U and Batislam E: Protective effects of udenafil citrate, piracetam and dexmedetomidine treatment on testicular torsion/detorsion-induced ischaemia/reperfusion injury in rats. Andrologia 48: 676-682, 2016

108. Raubach KH, Vlahov V, Wolter K and Bussmann WD Double-blind randomized multicenter study on the efficacy of trapidil versus isosorbide dinitrate in stable angina pectoris. Clin Cardiol 20: 483-488, 1997.

109. Bozlu M, Acar D, Cayan S, Aktas S and Tunckiran A: Protective effect of trapidil on long-term histologic damage in a rat model of testicular ischemia-reperfusion injury. World J Urol 27: $117-122,2009$

110. Inan M, Basaran U, Dokmeci D, Kanter M, Yalcin O, Aydogdu N and Turan N: Rosiglitazone, an agonist of peroxisome proliferator-activated receptor-gamma, prevents contralateral testicular ischaemia-reperfusion injury in prepubertal rats. Clin Exp Pharmacol Physiol 34: 457-461, 2007. 